\title{
Microwave Penetration and Attenuation in Desert Soil: A Field Experiment with the Shuttle Imaging Radar
}

\author{
TOM G. FARR, MEMBER, IEEE, CHARLES ELACHI, SENIOR MEMBER, IEEE, \\ PHILIP HARTL, MEMBER, IEEE, AND K. CHOWDHURY
}

\begin{abstract}
Receivers buried in the Nevada desert were used with the Shuttle Imaging Radar to measure microwave attenuation as a function of soil moisture in situ. Results agree closely with laboratory measurements of attenuation and suggest that penetration of tens of centimeters in desert soils is common for $L$-band $(1.2-\mathbf{G H z})$ radar.
\end{abstract}

\section{INTRODUCTION}

A LTHOUGH SIR-B was designed to produce radar images for a variety of studies, the radar signals also were used to measure microwave attenuation in natural soils at two sites in the Nevada desert near Hawthorne, $\mathrm{NV}$, by the use of receivers buried at different depths. This work was stimulated by the discovery in 1981 that images obtained by the SIR-B predecessor, SIR-A, over the Western Desert of Egypt and Sudan showed relic fluvial channels and other geologic features buried by a meter or more of sand [1]. Calculations showed that the extreme dryness of the soil allowed this penetration [2]. Follow-up investigations of that discovery [3] showed that particle size-frequency distribution of the sandy soil, lack of clays, extremely low moisture conditions, and the SIRA sensor parameters all contributed to maximizing SIR-A signal penetration. Quantitative measurements of microwave attenuation in soils however, have been done mostly in laboratory apparatus in which the material is packed into a waveguide [4]. The objective for the experiment described here was to directly measure microwave attenuation as a function of moisture content, in situ in natural soils in order to support concurrent searches for buried features in SIR-B images.

\section{Descriptions of the Sites}

Two sites were used during the SIR-B mission: site $A$ was about $10 \mathrm{~km}$ east of the town of Mina, NV, at $38^{\circ}$ $26.8^{\prime} \mathrm{N}, 118^{\circ} 00^{\prime} \mathrm{W}$; and site $B$ was about $10 \mathrm{~km}$ south of Mina, at $38^{\circ} 16.7^{\prime} \mathrm{N}, 118^{\circ} 6.4^{\prime} \mathrm{W}$. The area was

Manuscript received November 21, 1985; revised February 3, 1986. This work was carried out by the Jet Propulsion Laboratory, California Institute of Technology, under contract with NASA.

T. G. Farr and C. Elachi are with the Jet Propulsion Laboratory, California Institute of Technology, Pasadena, CA 91109.

P. Hartl and K. Chowdhury are with the University of Stuttgart, Stuttgart, West Germany.

IEEE Log Number 8608588

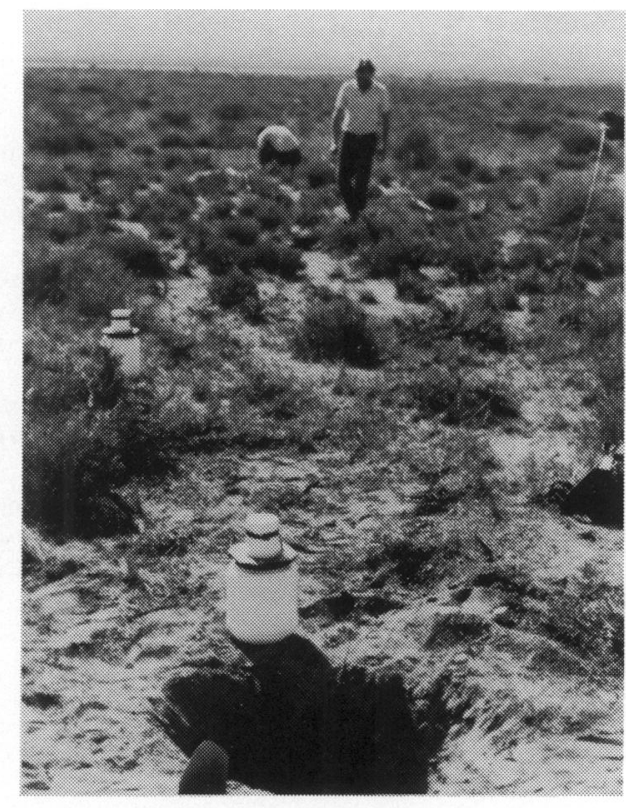

Fig. 1. View of the terrain typical to this study. In the foreground is a receiver in its protective case. The antenna is in the upper housing and a ground plane separates it from the electronics below. The data collection unit can be glimpsed beside the crouching figure in the background.

chosen because several parallel and crossing passes of SIR-B were planned there. The area has an arid climate, averaging about $250 \mathrm{~mm}$ of precipitation per year. Rainfall for June through September 1984, averaged $11 \mathrm{~mm}$ per month at Hawthorne, NV. The last rain recorded at Hawthorne before the flight was $1 \mathrm{~mm}$ on September 19 . Thus, it was expected that some microwave penetration of the soils would be observed.

Site $A$ was situated on an alluvial terrace lying about 5 $m$ above the level of the adjacent wash. The area on which the receivers were deployed was flat, about $20 \times 100 \mathrm{~m}$, with a steep drop to the stream bed and road on two sides, and shallow gullies on the other side. The closest significant hills were approximately $5 \mathrm{~km}$ away. The surface was covered with limestone pebbles of a few centimeters in size. Vegetation was sparse, and covered about 15 percent of the surface. Fig. 1 is a general view of a similar site, showing typical vegetation coverage, the receivers, and the type of holes excavated for their burial. The sub- 
surface of site $A$ contained layers of fine and coarse rounded pebbles and cobbles, mostly less than $5 \mathrm{~cm}$, but with some cobbles up to $15 \mathrm{~cm}$.

Site $B$ was situated on a flat alluvial apron between Rhodes Salt Marsh and the Excelsior Mountains, which were about $5 \mathrm{~km}$ to the north. The surface was covered with patches of sand and small pebbles with a few rocks up to $10 \mathrm{~cm}$. Vegetation was patchy, and covered about 15 percent of the surface.

\section{Description of the Receivers}

The receivers, built at the University of Stuttgart, were designed to be compact and rugged enough for field use. The antenna, receiver electronics, and power supply were housed in the plastic containers shown in Fig. 1. Signals were sent to and from the receivers via optical fiber cables. The receivers were controlled and data stored by a hand-held computer through an analog-to-digital converter $(\mathrm{ADC})$ interface. The controller is also visible in Fig. 1.

After reception by the crossed-dipole antenna, the received power was converted to a dc voltage. This dc voltage was then applied to a voltage-controlled oscillator, and the resulting frequency was sent via the optical fiber cable to the ADC and an 8-bit counter in the controller. The output of the counter represented the power density at the receiver after the measured gain pattern of the receiver antenna was factored in. This output was sampled in 100-ms increments for about $2.5 \mathrm{~min}$, and stored in computer memory.

\section{Results}

The recorded data were output on paper tape as a function of time. Each chart was then composed of the reproduction of the azimuth antenna pattern of SIR-B, as the Shuttle flew overhead, and the attenuation of the transmitted power according to the deployment mode of the individual receiver (Fig. 2). Dividing the difference between the power observed at two receivers by the path length between them yielded the attenuation as a function of path length. Table I shows the attenuation as a function of path length for several data takes for the sites $A$ and $B$. The values in Table I also can be used to calculate attenuation coefficient, skin depth, and penetration depth using equations found in Ulaby et al. [5, p. 847]. This analysis assumes that scattering in the soil volume is negligible compared to attenuation. We can use [5, eq. 11.39] to express the power at depth $z$

$$
P(z)=P(0+) \exp \left[-\int_{0}^{z} k_{e}\left(z^{\prime}\right) d z^{\prime}\right]
$$

where $P(0+)$ is the power just below the surface, and $k_{e}$ is the extinction coefficient. If scattering in the soil volume can be ignored, if the extinction coefficient is constant with depth, and if we carry out the calculation between two buried receivers at depths $z 1$ and $z 2$, then the equation reduces to

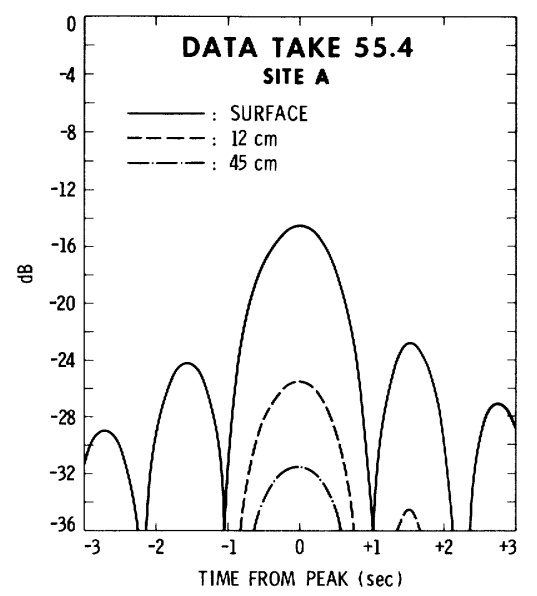

(a)

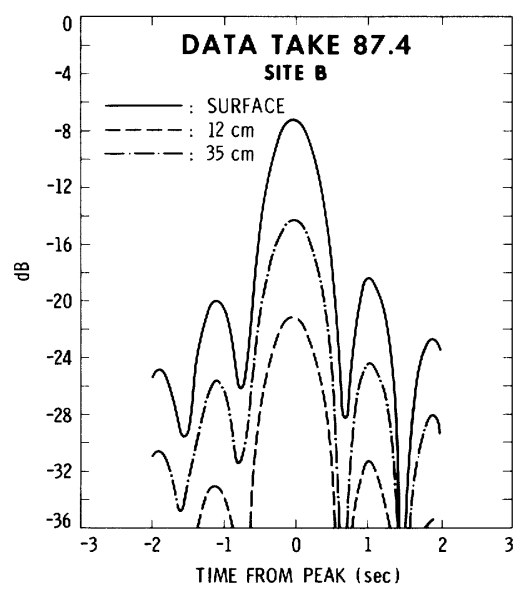

(b)

Fig. 2. Graphs showing the received data as a function of time. The uppermost curves for each site were collected by receivers deployed above the surface, and the lower curves by receivers buried at the indicated depths. (a) From data take 55.4 , site $A$. Note the relatively wide azimuth antenna pattern, due to the large incidence angle and the fact that the site was about $2^{\circ}$ off the center of the radar beam. (b) From data take 87.4 , site $B$. The narrower pattern was the result of a smaller incidence angle.

$$
P(z 2)=P(z 1) \exp \left(-2 \alpha \int_{z 1}^{z 2} d z^{\prime}\right)
$$

where the attenuation coefficient $\alpha=k_{e} / 2$. Solving for $\alpha$ gives

$$
\alpha=\frac{10 \log P(z 2)-10 \log P(z 1)}{20(z 2-z 1)} .
$$

$10 \log P(z)$ was the value measured by the receivers. The values presented in Table I as attenuation were calculated from the difference between the receiver measurements, divided by the difference in path length between them. Thus, the values reported in Table I can be converted to $\alpha$ by dividing by 20 .

Since the radar waves enter the soil at an angle, the path length difference between receivers 1 and 2 must be used instead of their depths. Furthermore, because the index of refraction of the soil is different from air, Snells Law must be used to correct the path lengths derived from simple 


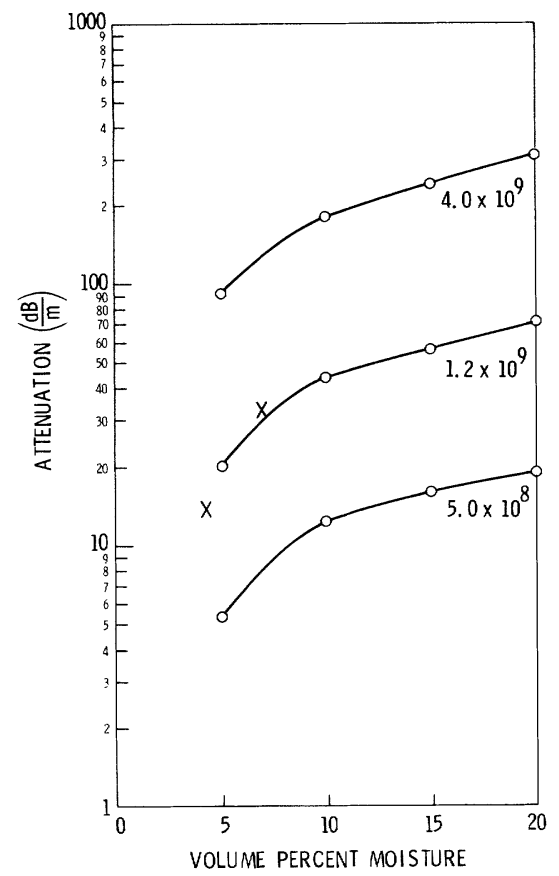

Fig. 3. A reproduction of a portion of Hoekstra and Delaney [4, Fig. 12], showing their measurements of attenuation as a function of volume moisture content for 0.5 and $4.0 \mathrm{GHz}$. An interpolation between these two curves (see text) yields the curve labeled $1.2 \mathrm{GHz}$, with which our data points (crosses) can be compared.

TABLE I

\begin{tabular}{|c|c|c|c|c|c|c|c|c|c|}
\hline Site & $\begin{array}{l}\text { data } \\
\text { take }\end{array}$ & $\begin{array}{l}\text { inc. } \\
\text { angle } \\
\text { (deg.) }\end{array}$ & $\begin{array}{l}\text { measured } \\
\text { power } \\
(\mathrm{dB})\end{array}$ & $\begin{array}{l}\text { receiver } \\
\text { depth } \\
(\mathrm{cm})\end{array}$ & $\begin{array}{l}\text { path } \\
\text { length } \\
(\mathrm{cm})\end{array}$ & $\underset{(\mathrm{dB} / \mathrm{m})}{\text { attenuation }}$ & $\begin{array}{c}\text { weight } \$ \\
\text { moisture } \\
\left(\mathrm{gH}_{2} \mathrm{O} / \mathrm{g} \text { soil) }\right.\end{array}$ & $\begin{array}{c}\text { penetration } \\
\text { depth }(\mathrm{m}) \delta_{\mathrm{p}}\end{array}$ & 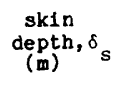 \\
\hline \multirow{2}{*}{ A } & \multirow{2}{*}{39.4} & \multirow{2}{*}{60.7} & -28.0 & 12 & 14 & \multirow{2}{*}{11.8} & \multirow{2}{*}{2.8} & \multirow{2}{*}{0.85} & \multirow{2}{*}{1.7} \\
\hline & & & -32.5 & 45 & 52 & & & & \\
\hline \multirow{2}{*}{ A } & \multirow{2}{*}{55.4} & \multirow{2}{*}{52.9} & -25.4 & 12 & 13.5 & \multirow{2}{*}{16.3} & \multirow{2}{*}{2.8} & \multirow{2}{*}{0.61} & \multirow{2}{*}{1.2} \\
\hline & & & -31.5 & 45 & 51 & & & & \\
\hline \multirow{2}{*}{ B } & \multirow{2}{*}{82.2} & \multirow{2}{*}{22.6} & -13.1 & 12 & 12 & \multirow{2}{*}{36.2} & \multirow{2}{*}{4.6} & \multirow{2}{*}{0.28} & \multirow{2}{*}{0.56} \\
\hline & & & -21.8 & 35 & 36 & & & & \\
\hline \multirow{3}{*}{ B } & \multirow{3}{*}{87.4} & \multirow{3}{*}{27.9} & -14.4 & 12 & 12.2 & \multirow{3}{*}{28.9} & \multirow{3}{*}{4.6} & \multirow{3}{*}{0.35} & \multirow{3}{*}{0.70} \\
\hline & & & -21.2 & 35 & & & & & \\
\hline & & & & & & & & & \\
\hline
\end{tabular}

geometry. Thus

$$
\text { path length }=z / \cos \left[\sin ^{-1}\left(\sin \theta_{i} / n\right)\right]
$$

where $n$ is the index of refraction. The values reported in Table I as path lengths have taken refraction into account with the assumption that the index of refraction is $\sqrt{3}$ (real dielectric constant is 3 ).

Other quantities of interest now can be calculated from

$\alpha$

$$
\begin{aligned}
\text { penetration depth } & =\delta_{p}=1 /(2 \alpha) \\
\text { skin depth } & =\delta_{s}=1 / \alpha .
\end{aligned}
$$

These are shown in Table I for the two sites.

Moisture content also was measured at several depths both at the time of burial and recovery of the receivers. The average of several measurements at depths between the two receivers are shown in Table I. The measurements of moisture content were made on the basis of weight (in grams $\mathrm{H}_{2} \mathrm{O} / \mathrm{g}$ soil); but the quantity used for comparison with microwave attenuation is volume percent moisture (grams $\mathrm{H}_{2} \mathrm{O} / \mathrm{cm}^{3}$ soil). To convert weight percent to volume percent, we have used an average value of $1.5 \mathrm{~g} / \mathrm{cm}^{3}$ for the density of the sandy, unconsolidated soils-yielding 4.2 volume-percent moisture for site $A$, and 6.9 volume-percent moisture for site $B$. It should be noted that these moisture contents are significantly higher than those encountered in the study of the Egyptian Desert, where moisture contents were typically less than 1 weight percent. The values for attenuation as a function of volume moisture content now can be compared with those derived by Hoekstra and Delaney [4]. Our values are shown plotted with their curves in Fig. 3. Hoekstra and Delaney [4] 
gave curves for 0.5 and $4.0 \mathrm{GHz}$, and not $1.2 \mathrm{GHz}$, so that in order to compare our results with theirs, we derived a curve at $1.2 \mathrm{GHz}$ by interpolation. The interpolation is not only a function of frequency, however, since the complex dielectric constant also varies with frequency. Ulaby et al. [5] give the effect of frequency and the real $\left(\epsilon^{\prime}\right)$ and imaginary $\left(\epsilon^{\prime \prime}\right)$ parts of the dielectric constant on the attenuation as

$$
\text { attenuation }=C f\left(\epsilon^{\prime \prime} / \sqrt{\epsilon^{\prime}}\right)
$$

where $C$ is a constant. We have used this relationship and values for $\epsilon^{\prime}$ and $\epsilon^{\prime \prime}$ given in [4] to derive the curve shown in Fig. 3 for $1.2 \mathrm{GHz}$. Fig. 3 shows the close agreement between our measurements of in situ attenuation versus soil moisture and the results of Hoekstra and Delaney [4]. Ulaby et al. [5, Fig. 11.26] show the relationship between penetration depth $\delta_{p}$ and volume moisture content for $10.0,4.0$, and $1.3 \mathrm{GHz}$. Our results also closely match theirs for the $1.3-\mathrm{GHz}$ case.

\section{Conclusions, Future Work}

In situ measurements of microwave attenuation in desert soils can be made in the field with compact receivers, and results agree closely with laboratory measurements. These measurements support the observations of subsurface features visible in radar images obtained at $L$-band $(1.2 \mathrm{GHz})$ over desert areas. At two sites in Nevada the skin depth ranged from 0.7 to $1.7 \mathrm{~m}$, even though the soil moisture was much higher than that found in hyperarid regions of the world.

Future work will involve different techniques of excavation in order to disturb the overlying soil as little as possible. In addition, more sites with a greater range of soil moisture are planned to be visited. Aircraft, as well as spaceborne radars will be used; however, spaceborne radars have the advantage of covering a larger area with a constant power density, assuring more consistent results. Polarization sensitivity is planned to be added to the receivers by replacement of the crossed-dipole antenna, in order to study the polarization dependence of attenuation in desert soils.

Measurement of microwave attenuation is not limited to desert soils, and plans call for both permafrost in Alaska and ice in Antarctica or Greenland to be similarly probed. Both permafrost and fresh-water ice have very low attenuation coefficients, similar to dry desert soils.

\section{ACKNOWLEDGMENT}

The authors would like to thank A. Gabriel and K. Nathan of JPL, and D. Massonnet of CNES, France for assistance in the field; and the SIR-B Mission Operations Team for updates during the mission, without which this study could not have been accomplished.

\section{REFERENCES}

[1] J. F. McCauley, G. G. Schaber, C. S. Breed, M. J. Grolier, C. V. Haynes, B. Issawi, C. Elachi, and R. Blom, "'Subsurface valleys and geoarchaeology of the eastern Sahara revealed by shuttle radar," Science, vol. 218, pp. 1004-1020, 1982.
[2] C. Elachi, L. E. Roth, and G. G. Schaber, "Spaceborne radar subsurface imaging in hyperarid regions," IEEE Trans. Geosci. Remote Sensing, vol. GE-22, pp. 383-388, 1984.

[3] G. G. Schaber, J. F. McCauley, C. S. Breed, and G. R. Olhoeft, "Space shuttle imaging radar: Physical controls of signal penetration and subsurface backscattering in the eastern Sahara," IEEE Trans. Geosci. Remote Sensing, this issue, pp. 603-623.

[4] P. Hoekstra and A. Delaney, "Dielectric properties of soils at UHF and microwave frequencies," J. Geophys. Res., vol. 79, pp. 16991708,1974

[5] F. T. Ulaby, R. K. Moore, and A. K. Fung, Microwave Remote Sensing. Reading, MA: Addison-Wesley, 1982.

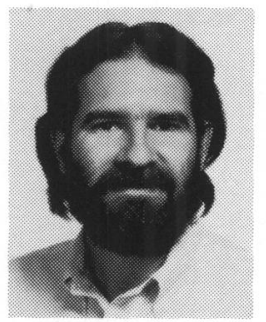

Tom G. Farr (M'84) received the B.S. degree in 1974 and the M.S. degree in 1976, both in geology from the California Institute of Technology, Pasadena, CA, and the Ph.D. degree in geology from the University of Washington in Seattle in 1981.

Throughout his Masters and Ph.D. work, he was employed by the Jet Propulsion Laboratory, at first working on airborne radar data of arctic sea ice and later on Seasat and SIR-A images of geologic targets. He is currently an Investigator on the SIR-B experiment, which has involved the development of new techniques for the extraction of quantitative geologic information from multiincidence angle radar images. His current research interests include the improvement of electromagnetic scattering models for rough geologic surfaces and subsurfaces, and the use of multiparameter radar systems to quantitatively predict surface and subsurface properties on earth and other planets.

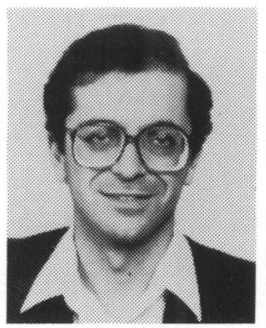

Charles Elachi (M'71-SM'82) was born in Lebanon in 1947. He received the Ingenieur degree with honors in radioelectricity and the "Prix de la Houille Blanche" from the Polytechnic Institute of Grenoble, Grenoble, France, in 1968 and the B.S. degree in physics from the University of Grenoble in 1968. He received the M.S. and Ph.D. degrees in electrical sciences from the California Institute of Technology, Pasadena, in 1969 and 1971, respectively.

He has worked at the Physical Spectrometry Laboratory, University of Grenoble, France, on plasma in microwave cavities. He was a Teaching Assistant at the California Institute of Technology in 1969. In 1970, he joined the Space Sciences Division, Jet Propulsion Laboratory, Pasadena, where he is presently the Division Manager and a Senior Research Scientist involved in investigating spacecraft-borne scientific experiments for planetary and Earth studies using coherent radar techniques. Since 1980, he has been the Manager for Radar Development, which covers all aspects of the radar remote-sensing program at JPL. He was the Principal Investigator on the Shuttle Imaging Radar (SIR-A) which flew in 1981, and the follow-on SIR-B experiment (1984). He is the Project Scientist of the SIR project and a Team member on the Magellan (Venus Radar Mapper) mission. He has been involved in studying theoretical electromagnetic problems related to scattering from natural terrain, remote sensing, stratified media, space-time periodic media, and DFB lasers. He has 170 papers, patents, reports, and conference presentations in the above fields. He also lectures at the California Institute of Technology on the "Physics of Remote Sensing,"

In 1973, Dr. Elachi was the first recipient of the R. W. P. King award. In 1980 and 1982, he received the Autometric Award of the American Phogrammetric Society. In 1982 he received the NASA Exceptional Scientific Achievement Medal and, in 1985, the W. T. Pecora award. 


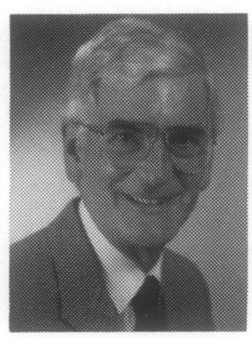

Philip Hartl (M'83) was born in Viechtach, Germany on December 14, 1928. He received the M.S. degree from the Techn. University Munich, in 1953, the doctoral degree from the University Stuttgart in 1961, and the degree of Dr.-Ing. habil. from the Tech. University Munich in 1973.

From 1950 to 1955 , he worked for the Siemens and Halske Company in the area of data transmission. He then joined the German Aeronautical Research Establishment DFVLR where his R\&D activities centered around navigation and telecommunication and various satellite and sounding rocket projects. After several years as Research Associate and Supervisor, he became Division Chief for telecommunication theory, then Director of the Institute for Sat- ellite Electronics, and finally director of the DFVLR Research Center Oberpfaffenhofen. In 1974 he joined the faculty at the Tech. University Berlin, as Professor of satellite technology. Since May of 1983, he has been a Professor at the University Stuggart and director of the Institute for Navigation. His current fields of research encompass navigation, remote sensing, and data processing.

K. Chowdhury, photograph and biography not available at the time of publication. 